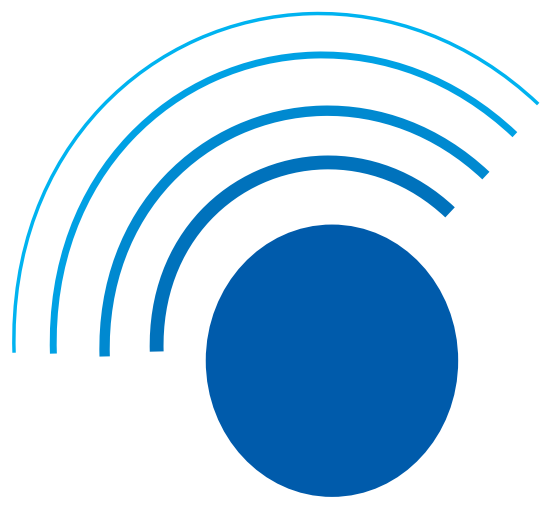

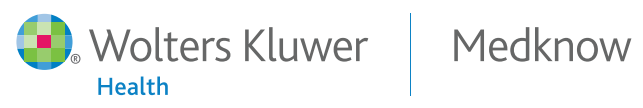
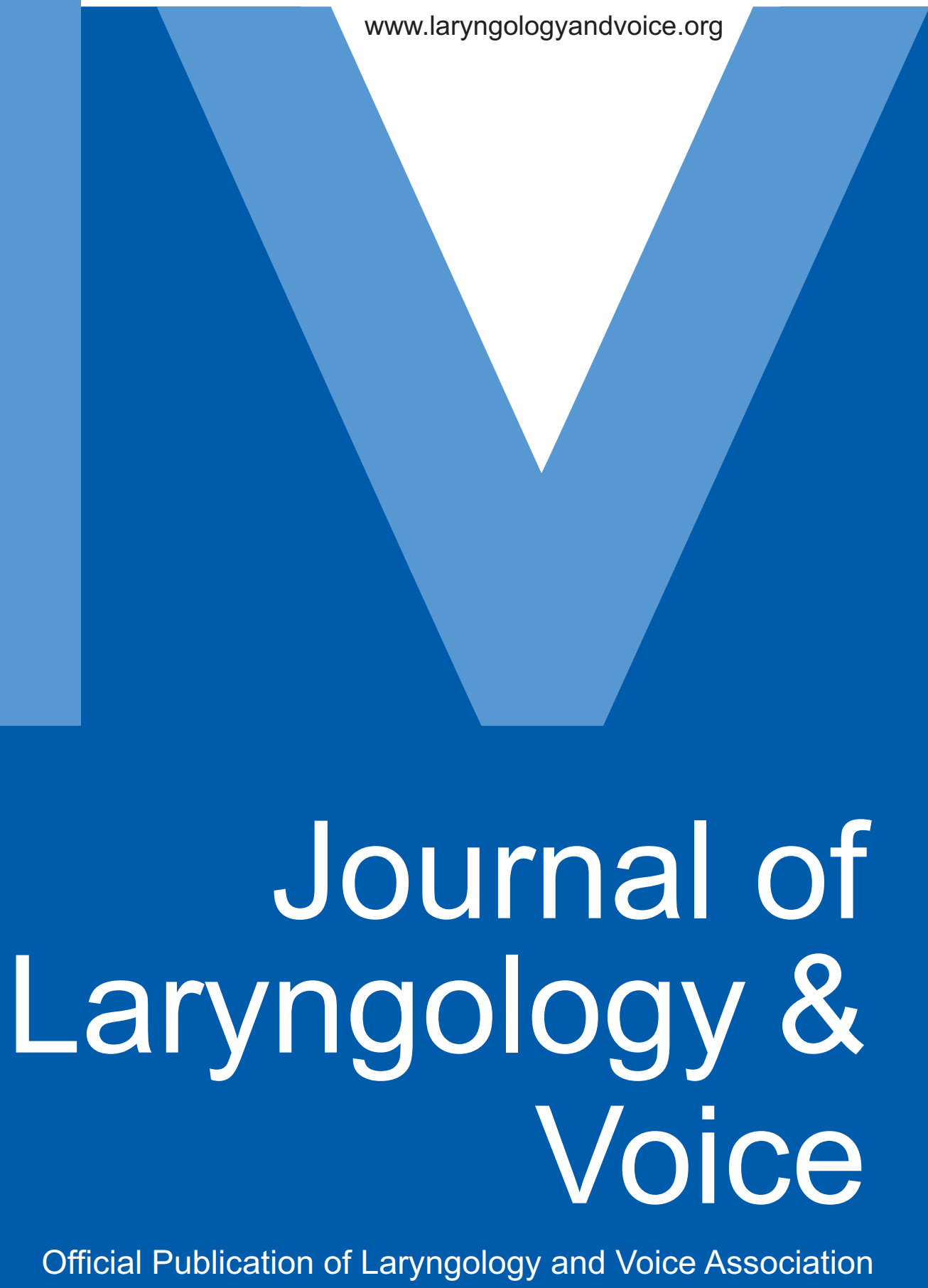

Vol 4 / Issue 1 / Jan-Jun 2014 


\section{Voice acoustic profile of males exposed to occupational infrasound and low-frequency noise}

Ana P. Mendes ${ }^{1,2}$, Íris Bonança ${ }^{1}$, Ana Jorge ${ }^{3}$, Mariana Alves-Pereira ${ }^{4}$, Nuno A. A. Castelo Branco ${ }^{5}$, Marlene Caetano ${ }^{1}$, Nádia Oliveira ${ }^{1}$, Andreia Graça ${ }^{6}$, Carolina Santos ${ }^{6}$, Renata Ferraria ${ }^{1}$

${ }^{1}$ Health School of Polytechnic Institute of Setúbal, Setúbal, ${ }^{2}$ IETEA-Institute of Electronics and Telematics Engineering of Aveiro, Aveiro, ${ }^{3}$ Institute of Accounting and Administration of Lisbon, Lisbon, ${ }^{4} \mathrm{CIEG}-\mathrm{School}$ of Economics and Management and ERISA School of Health Sciences, Lusófona University, Lisbon, ${ }^{5}$ Human Performance Center, Alverca, ${ }^{6}$ LINADEM-League for the Study and Support for Social Inclusion, Lisbon, Portugal

\begin{abstract}
Background: Vibroacoustic disease (VAD) is a systematic pathology characterized by the abnormal growth of extra-cellular matrices in the absence of inflammatory processes, namely collagen and elastin, both of which are abundant in the basement membrane zone of the vocal folds. VAD can develop due to long-term exposure to infrasound and low-frequency noise (ILFN, <500 Hz). Mendes et al. (2006, 2008 and 2012) revealed that ILFN-exposed males and females presented an increased fundamental frequency $\left(F_{0}\right)$, decreased jitter \%, and reduced maximum phonation frequency range, when compared with normative data. Temporal measures of maximum phonation time and S/Z ratio were generally reduced. Study Aims: Herein, the same voice acoustic parameters of 48 males, 36 airline pilots and 12 cabin crewmembers (age range 25-60 years) were studied, and the effects and interaction of age and years of ILFN exposure were investigated within those parameters. ILFN-exposure time (i.e. years of professional activity) ranged from 3.5 to 36 years. Materials and Methods: Spoken and sung phonatory tasks were recorded with a DA-P1 Tascam DAT and a C420III PP AKG head-worn microphone, positioned at $3 \mathrm{~cm}$ from the mouth. Acoustic analyses were performed using KayPENTAX Computer Speech Lab and Multi-Dimensional Voice Program. Results: Results revealed that even though pilots and cabin crewmembers were exposed to occupational environments with distinct (ILFN-rich) acoustical frequency distributions and sound pressure levels, differences in the vocal acoustic parameters were not evident. Analyzing data from both professional groups $(N=48)$ revealed that $F_{0}$ increased significantly with the number of years of professional activity. Conclusion: These results strongly suggest that the number of years of professional activity (i.e. total ILFN exposure time) had a significant effect on $\mathrm{F}_{0}$. Furthermore, they may reflect the histological changes specifically observed on the vocal folds of ILFN-exposed professionals.
\end{abstract}

Key words: Infrasound and low frequency noise-exposure, vibroacoustic disease, voice acoustic analysis, vocal folds

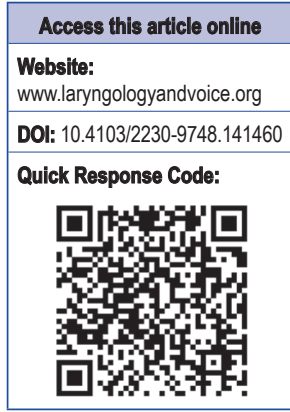

\section{INTRODUCTION}

Vibroacoustic disease (VAD) is a systemic pathology caused by long-term exposure to infrasound and low-frequency noise (ILFN), specifically frequencies below $500 \mathrm{~Hz}^{[1,2]}$ which affects organs and systems, particularly the respiratory tract. ${ }^{[3,4]}$ VAD is characterized by abnormal growth of extra-cellular

\footnotetext{
Address for correspondence:

Dr. Íris Bonança, Escola Superior de Saúde | Instituto Politécnico de Setúbal, Campus do IPS, Estefanilha, 2914-503 Setúbal, Portugal. E-mail: iris.bonanca@ess.ips.pt
}

matrices as seen in thickening of cardiac structures (pericardium, cardiac valves and blood vessel walls, as observed through echocardiography, light and electron microscopy), and of respiratory system structures (pleura and trachea). ${ }^{[1,5-7]}$

In ILFN-exposed animal models (Wistar rats) also disclosed thickened respiratory tract structures due to the abnormal growth of collagen ${ }^{[8]}$ Respiratory and phonatorycomplaints in VAD patients include non-productive cough, hoarseness, repeated upper and lower respiratory infections, bronchitis (in smokers and non-smokers alike) and respiratory insufficiency in ILFN-exposed older workers. ${ }^{[2]}$ Standard lung 
function tests, such as vital capacity, tidal volume, forced expiratory volume and peak expiratory flow, were within normal limits. However, focal lung fibrosis was identified in a group of ILFN-exposed workers. ${ }^{\mid 9,10]}$

Histologically, collagen is one of the constituents of vocal folds. Basal cells composed of proteins extend from the plasma membrane to the lamina densa, which is composed by Type IV collagen fibers. From the lamina densa to the sub-basement membrane area there are fibers wrapped by Type III collagen. Injury, nodules or other benign tumors can damage these fragile connecting links. ${ }^{[11,12]}$

Voice acoustic analysis is frequently used to track down changes in voice production as a consequence of physiological changes of the laryngeal system. ${ }^{[13]}$ Fundamental frequency $\left(\mathrm{F}_{0}\right)$, vocal intensity, perturbation of the frequency (jitter), perturbation of amplitude (shimmer), harmonic-to-noise ratio (HNR), and maximum phonational frequency range (MPFR) are acoustic parameters used to pinpoint these changes. $F_{0}$ reflects the efficiency of the phonatory system in terms of its biomechanical and aerodynamic physical characteristics. Perturbation measures (jitter and shimmer) reflect the slight differences of mass, tension, neural control and biomechanical characteristics of vocal folds. ${ }^{[14]}$ HNR reflects the aperiodic signal or vibration generated at or near the glottal source. MPFR reflects the physical limits of the phonatory system. Temporal measures such, as maximum phonation time (MPT) and $S / Z$ ratio are complementary measures that reflect the efficient coordination between the respiratory and phonatory system. Lastly, voice tremor measures the integrity of the neural control for voice production. Given the sensitivity of these measures to changes in laryngeal/ respiratory system coordination, and the specific features of the organic response to ILFN exposure, voice acoustic analysis reflects ILFN-induced changes in respiratory tract morphology. Hence, voice acoustic analysis provides a fast, easy, low cost, user friendly, and non-invasive method for screening, evaluating, and monitoring VAD risk groups. ${ }^{[15-18]}$

Previous studies with VAD diagnosed subjects and ILFN professional workers revealed different pattern of spectral (speaking and singing tasks), temporal and perturbation measures when compared with normative data for males and females: ${ }^{[15]}$ The mean $\mathrm{F}_{0}$ of three sustained vowels was slightly higher, while jitter mean values were all below normative mean, HNR means were very high, MPT was below norms and MPFR was severely reduced at both ends and range. This specific pattern may indicate the presence of histological changes within the laryngeal system, particularly on the vocal folds, and related to long-term ILFN exposure. ${ }^{\mid 15-18]}$
Pilots and crew members are subjected to distinct acoustical environments while working onboard commercial aircraft: Pilots are subjected to statistically significantly higher infrasound $(<20 \mathrm{~Hz})$ that are crewmembers. Nevertheless, it is not yet known whether this difference in occupational environments could be mirrored by voice acoustic parameters. Simultaneously, it is still unclear the effect of age and years of professional activity could also have upon these voice measures. ${ }^{[19]}$ Accordingly, the questions are: (1) Is there a difference in voice acoustic measures of pilots and cabin crew members, and (2) does age and years of ILFN professional exposure exert a significant effect on them.

The present study aims to: (1) Sketch a voice acoustic profile of males exposed to occupational ILFN; (2) Analyze the effect of professional activity years of ILFN-exposure on the voice acoustic parameters of these males; and (3) Analyze the interaction of age and professional activity years of ILFN-exposure on voice acoustic parameters of these exposed males.

\section{MATERIALS AND METHODS}

Most of the procedures utilized in this research have been described elsewhere, ${ }^{[16-18]}$ therefore, herein they will only be briefly reviewed. Because subjects, tasks, and recording equipment were common to all of the several procedures, they will be discussed first.

\section{Subjects}

Forty-eight male subjects voluntarily participated in this study: 36 commercial airline pilots (CAP) (mean age: 41, range 25-60 years) and 12 airline cabin crewmembers (ACC) (mean age: 43 , range $29-60$ years). In the CAP's group, seven were smokers, 13 reported moderate alcohol intake (i.e. 1-2 glasses/ day for several years), one subject had voice complaints and three presented respiratory perturbations characterized by rhinitis, bronchitis and allergies. In the ACC's group, five were smokers, nine had moderate alcohol intake, two subjects reported allergy-related respiratory complaints, five reported voice complaints, and two were diagnosed with laryngeal papilloma and vocal polyps [Table 1]. Overall, CAP and ACC are classified as Type II - Professional voice, where voice is an integral part of their profession and when a moderate voice problem may compromise their work performance. ${ }^{[20]}$ The mean of years of professional activity was 19 for both groups and ranged from 3.5 to 36 and 7 to 36 years, for CAP and ACC, respectively [Tables 2 and 3].

Subjects were annually required to perform a complete hearing and middle ear function evaluation. All presented hearing and middle ear function within normal limits. 


\begin{tabular}{|c|c|c|c|c|c|c|c|c|}
\hline $\begin{array}{l}\text { Case } \\
\text { no. }\end{array}$ & ID & Age & Profession & $\begin{array}{c}\text { Years of } \\
\text { professional activity }\end{array}$ & $\begin{array}{c}\text { Activity } \\
\text { smoker }(\mathrm{Y} / \mathrm{N})\end{array}$ & $\begin{array}{c}\text { Alcoholic } \\
\text { habits (Y/N) }\end{array}$ & $\begin{array}{c}\text { Respiratory } \\
\text { complaints }(\mathrm{Y} / \mathrm{N})\end{array}$ & $\begin{array}{c}\text { Vocal } \\
\text { complaints }(\mathrm{Y} / \mathrm{N})\end{array}$ \\
\hline 1 & $\mathrm{JA} 1$ & 48 & CAP & 25 & $\mathrm{~N}$ & $Y$ & $\mathrm{~N}$ & $\mathrm{~N}$ \\
\hline 2 & $\mathrm{DL}$ & 35 & CAP & 15 & $Y$ & $\mathrm{~N}$ & $\mathrm{~N}$ & $\mathrm{~N}$ \\
\hline 3 & $\mathrm{RP}$ & 42 & CAP & 20 & $\mathrm{~N}$ & Y & $\mathrm{N}$ & $\mathrm{N}$ \\
\hline 4 & $J G$ & 42 & CAP & 24 & $\mathrm{~N}$ & $\mathrm{~N}$ & $\mathrm{~N}$ & $\mathrm{~N}$ \\
\hline 5 & EB & 51 & CAP & 17 & $\mathrm{~N}$ & $\mathrm{~N}$ & $\mathrm{~N}$ & $\mathrm{~N}$ \\
\hline 6 & $J P$ & 39 & CAP & 21 & $\mathrm{~N}$ & $Y$ & $\mathrm{~N}$ & $\mathrm{~N}$ \\
\hline 7 & $\mathrm{CL}$ & 45 & CAP & 26 & $Y$ & $\mathrm{~N}$ & $\mathrm{~N}$ & $N$ \\
\hline 8 & $\mathrm{MO}$ & 40 & CAP & 11 & $\mathrm{~N}$ & $Y$ & $\mathrm{~N}$ & $\mathrm{~N}$ \\
\hline 9 & AY & 44 & CAP & 26 & $\mathrm{~N}$ & $Y$ & $\mathrm{~N}$ & $N$ \\
\hline 10 & MD & 26 & CAP & 6 & $\mathrm{~N}$ & $\mathrm{~N}$ & $\mathrm{~N}$ & $N$ \\
\hline 11 & $\mathrm{NC}$ & 28 & CAP & 3,5 & N & $\mathrm{N}$ & Y & $\mathrm{N}$ \\
\hline 12 & ND & 39 & CAP & 22 & $\mathrm{~N}$ & $\mathrm{~N}$ & $\mathrm{~N}$ & $\mathrm{~N}$ \\
\hline 13 & $\mathrm{MB}$ & 44 & CAP & 24 & $\mathrm{~N}$ & $\mathrm{~N}$ & $\mathrm{~N}$ & $\mathrm{~N}$ \\
\hline 14 & $A C$ & 32 & CAP & 7 & $\mathrm{~N}$ & $Y$ & $\mathrm{~N}$ & $\mathrm{~N}$ \\
\hline 15 & $\mathrm{CR}$ & 48 & CAP & 15 & $Y$ & $Y$ & Y & $N$ \\
\hline 16 & CB & 56 & CAP & 35 & $\mathrm{~N}$ & $\mathrm{~N}$ & $\mathrm{~N}$ & $N$ \\
\hline 17 & PC & 42 & CAP & 22 & $\mathrm{~N}$ & $\mathrm{~N}$ & $\mathrm{~N}$ & $\mathrm{~N}$ \\
\hline 18 & $\mathrm{JB}$ & 43 & CAP & 26 & $\mathrm{~N}$ & $\mathrm{~N}$ & $\mathrm{~N}$ & $\mathrm{~N}$ \\
\hline 19 & GR & 29 & CAP & 12 & N & $\mathrm{N}$ & $\mathrm{N}$ & $\mathrm{N}$ \\
\hline 20 & $\mathrm{FL}$ & 45 & CAP & 25 & $\mathrm{~N}$ & $\mathrm{~N}$ & $\mathrm{~N}$ & $\mathrm{~N}$ \\
\hline 21 & JV & 35 & CAP & 11 & $\mathrm{~N}$ & $N$ & $N$ & $N$ \\
\hline 22 & JA2 & 42 & CAP & 19 & $\mathrm{~N}$ & $\mathrm{~N}$ & $\mathrm{~N}$ & $\mathrm{~N}$ \\
\hline 23 & JC1 & 42 & CAP & 20 & $Y$ & $Y$ & $\mathrm{~N}$ & $\mathrm{~N}$ \\
\hline 24 & LB & 40 & CAP & 15 & $\mathrm{~N}$ & Y & $\mathrm{N}$ & $\mathrm{N}$ \\
\hline 25 & AP & 48 & CAP & 24 & $\mathrm{~N}$ & $Y$ & $\mathrm{~N}$ & $Y$ \\
\hline 26 & MV & 35 & CAP & 6 & $\mathrm{~N}$ & $\mathrm{~N}$ & $\mathrm{~N}$ & $\mathrm{~N}$ \\
\hline 27 & LN & 44 & CAP & 23 & $\mathrm{~N}$ & $Y$ & $\mathrm{~N}$ & $N$ \\
\hline 28 & $\mathrm{FN}$ & 35 & CAP & 9 & $\mathrm{~N}$ & $\mathrm{~N}$ & $\mathrm{~N}$ & $N$ \\
\hline 29 & $\mathrm{JM}$ & 47 & CAP & 25 & $\mathrm{~N}$ & $\mathrm{~N}$ & $Y$ & $\mathrm{~N}$ \\
\hline 30 & $J \mathrm{~L}$ & 46 & CAP & 22 & N & $\mathrm{N}$ & $\mathrm{N}$ & $\mathrm{N}$ \\
\hline 31 & VS & 40 & CAP & 20 & $\mathrm{~N}$ & $\mathrm{~N}$ & $\mathrm{~N}$ & $\mathrm{~N}$ \\
\hline 32 & $J R$ & 41 & CAP & 24 & Y & $Y$ & $\mathrm{~N}$ & $\mathrm{~N}$ \\
\hline 33 & $A D$ & 60 & CAP & 36 & $\mathrm{~N}$ & $\mathrm{~N}$ & $\mathrm{~N}$ & $N$ \\
\hline 34 & $\mathrm{JC} 2$ & 41 & CAP & 25 & $Y$ & $Y$ & $\mathrm{~N}$ & $\mathrm{~N}$ \\
\hline 35 & $J D$ & 25 & CAP & 6 & $\mathrm{~N}$ & $\mathrm{~N}$ & $\mathrm{~N}$ & $\mathrm{~N}$ \\
\hline 36 & RA & 53 & CAP & 30 & Y & $\mathrm{N}$ & $\mathrm{N}$ & $\mathrm{N}$ \\
\hline 37 & $J \mathrm{R}$ & 60 & ACC & 35 & $Y$ & $Y$ & $Y$ & $\mathrm{~N}$ \\
\hline 38 & $\mathrm{CV}$ & 57 & ACC & 27 & $\mathrm{~N}$ & Y & $\mathrm{N}$ & Y \\
\hline 39 & CF & 59 & ACC & 34 & $\mathrm{~N}$ & $Y$ & $\mathrm{~N}$ & $Y$ \\
\hline 40 & RG & 32 & ACC & 10 & $\mathrm{~N}$ & $Y$ & $Y$ & $Y$ \\
\hline 41 & PB & 29 & ACC & 8 & $Y$ & $Y$ & $\mathrm{~N}$ & $\mathrm{~N}$ \\
\hline 42 & $\mathrm{JB} 1$ & 31 & $\mathrm{ACC}$ & 7 & $Y$ & $Y$ & $\mathrm{~N}$ & $\mathrm{~N}$ \\
\hline 43 & MA1 & 44 & ACC & 20 & $N$ & $Y$ & $\mathrm{~N}$ & $\mathrm{~N}$ \\
\hline 44 & LM2 & 60 & ACC & 33 & $Y$ & $Y$ & $\mathrm{~N}$ & $\mathrm{~N}$ \\
\hline 45 & NM & 35 & ACC & 10 & $Y$ & $\mathrm{~N}$ & $N$ & $\mathrm{~N}$ \\
\hline 46 & $\mathrm{HM}$ & 31 & ACC & 10 & $\mathrm{~N}$ & $\mathrm{~N}$ & $\mathrm{~N}$ & $Y$ \\
\hline 47 & $J D$ & 34 & ACC & 14 & $\mathrm{~N}$ & $\mathrm{~N}$ & $\mathrm{~N}$ & $\mathrm{~N}$ \\
\hline 48 & JB2 & 43 & ACC & 20 & $Y$ & $Y$ & $\mathrm{~N}$ & $Y$ \\
\hline
\end{tabular}

Legend $-\mathrm{CAP}=$ Commercial airline pilots; $\mathrm{ACC}=$ Airline commercial crewmembers; $\mathrm{Y}=\mathrm{Yes} ; \mathrm{N}=\mathrm{No}$

\begin{tabular}{|c|c|c|c|c|c|}
\hline \multicolumn{6}{|c|}{$\begin{array}{l}\text { Table 2: Mean and range of age and professional } \\
\text { activity (yrs) of commercial airline pilots and airline } \\
\text { commercial crewmembers }\end{array}$} \\
\hline \multirow[t]{2}{*}{ Groups } & \multirow[t]{2}{*}{$N$} & \multicolumn{2}{|c|}{ Age (years) } & \multicolumn{2}{|c|}{ Prof. Act. (years) } \\
\hline & & Mean & Range & Mean & Range \\
\hline CAP & 36 & 41 & $25-60$ & 19 & $3.5-36$ \\
\hline ACC & 12 & 43 & $29-60$ & 19 & $7-36$ \\
\hline Total & 48 & 42 & $25-60$ & 19 & $3.5-36$ \\
\hline
\end{tabular}

These two male, ILFN-exposed professional groups were treated as one since they did not present voice acoustic differences between them [Table 4].

\begin{tabular}{|c|c|c|c|c|}
\hline $\begin{array}{l}\text { Age } \\
\text { groups (years) }\end{array}$ & $\begin{array}{l}\text { Professional activity } \\
\text { intervals (years) }\end{array}$ & CAP & ACC & $N$ \\
\hline \multirow[t]{2}{*}{$<37$} & $<9$ & 5 & 2 & 7 \\
\hline & {$[9 ; 20]$} & 4 & 4 & 8 \\
\hline \multirow[t]{2}{*}[37;45]{} & {$[9 ; 20]$} & 3 & - & 3 \\
\hline & {$[20 ; 26]$} & 15 & 2 & 17 \\
\hline \multirow[t]{3}{*}{$>45$} & {$[9 ; 20]$} & 2 & - & 2 \\
\hline & {$[20 ; 26]$} & 4 & - & 4 \\
\hline & $\geq 26$ & 3 & 4 & 7 \\
\hline Total & & 36 & 12 & 48 \\
\hline
\end{tabular}

$\mathrm{CAP}=$ Commercial airline pilots; $\mathrm{ACC}=$ Airline commercial crewmembers 


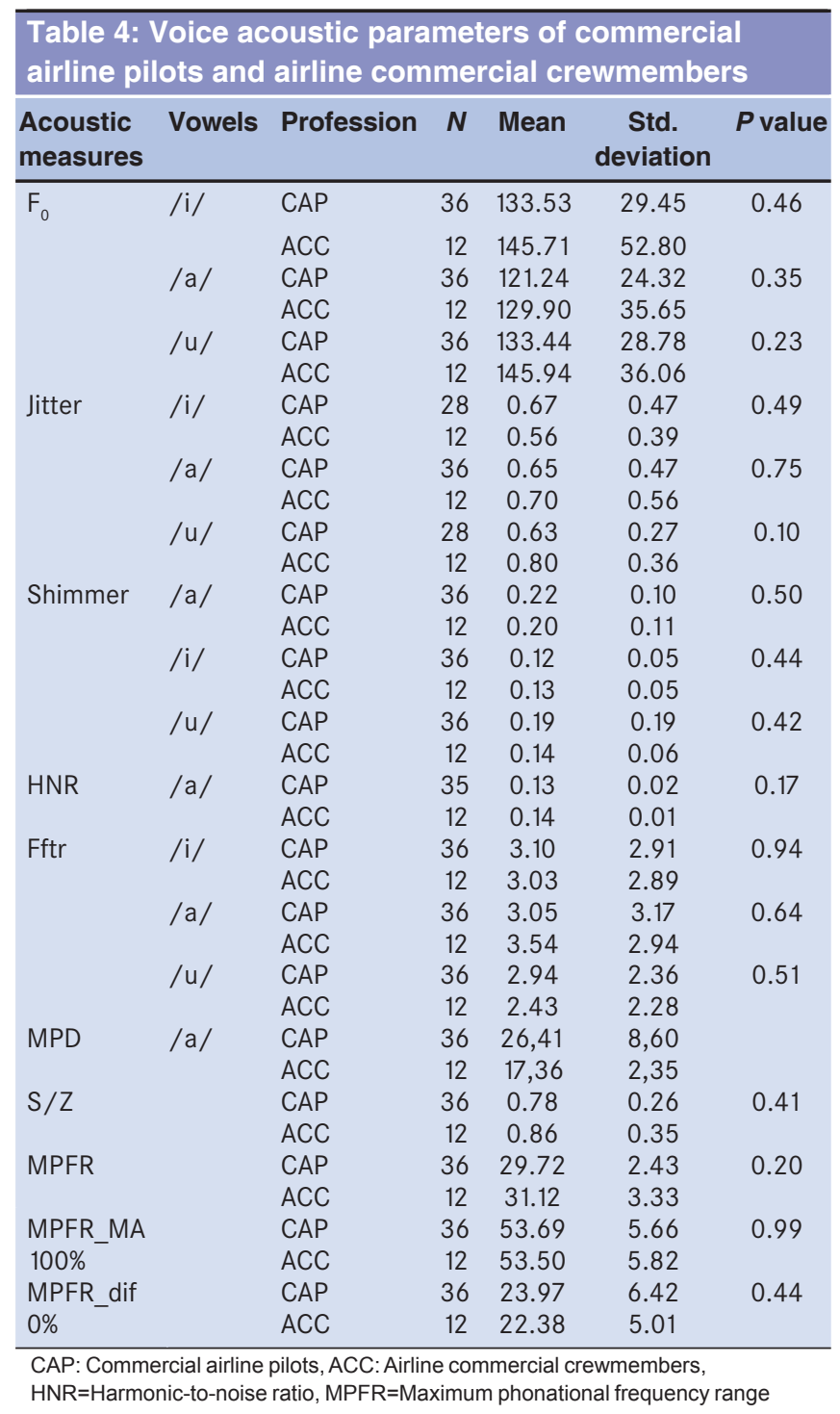

Phonatory tasks

Subjects performed speaking and singing tasks in the standing position. Before the recordings, all subjects briefly warmed-up their voice by performing phonational and dynamic ranges, as well as, by reading aloud the phonetically balanced text "O Sol". ${ }^{[21]}$ Speaking tasks included sustaining vowels and fricatives. Subjects were asked to sustain/i, a, u/three times each for 6 seconds. Even though six to 10 trials are recommended for perturbations measures ${ }^{[20]}$ only three trials of each task were performed to avoid subject fatigue. The sustained vowel task requires a stable condition of the pneumophonatory system, allowing an evaluation of this function's stability and permitting a comparison with the normative data. Subjects also sustained/a, s, z/three times each for as long as they could.

Sung tasks consisted of MPFR, which encompassed sustained/a/and frequencies from the lowest modal register to the highest falsetto register. Vocal fry was not included. ${ }^{[22,23]}$
A semitone chart and a piano-keyboard were used to provide reference frequencies and audio feedback to the researcher and the subject. The discrete-step task and the pitch-matching procedure were performed three times. ${ }^{[24]}$ Subjects were allowed a 1 -minute rest period between trials. The lowest and the highest sustained/a/represented the $0 \%$ and the $100 \%$ levels of the MPFR. ${ }^{[25]}$

\section{Equipment}

Phonatory tasks were recorded in a quiet environment $(<50 \mathrm{~dB})$ at the Associação de Pilotos Portugueses de Linhas Aéreas and at the Sindicato Nacional do Pessoal de Voo da Aviação Civil, in Lisbon. Voice productions were captured with an AKG C420 ${ }^{\text {III }}$ PP high-quality cardioid type headset microphone, placed $3 \mathrm{~cm}$ from the right corner of the mouth and at a $45^{\circ}$ degree angle. ${ }^{[26]}$ The acoustic signal was amplified with a phantom RANE MS-16. An Agilente 8494A attenuator was activated for loudphonations to avoid peak clipping. Voice samples were recorded to a portable Tascam DA-P1Digital Audiotape Recorder (DAT). For calibration purposes, a $500-\mathrm{Hz}$ tone of $80 \mathrm{~dB}$ SPL, at 3-cm distance from sound source to microphone, was recorded onto each digital audiotape. Prior to measuring each subject's productions, the calibration tone was digitized and served as a reference tone calculated by KayPENTAX Computer Speech Lab (CSL), model 4500..$^{27]}$

For the acoustic analyses, a HP dx5150 with the CSL external sound card was used with the Multi-Dimensional Voice Program (MDVP) software, model 5105. All samples were amplified with the Audacity software, model 1.2.6, and digitized at a rate of $25.0 \mathrm{kHz}$. The frequency values of the MPFR were converted to semitone levels (Eq. 1) since the music frequency scale is logarithmic in nature ${ }^{[28]}$ :

$40 * \log 10(\mathrm{f} 2 / \mathrm{f} 1)(\mathrm{f} 1)=(\mathrm{ST}$, re: $16.35 \mathrm{~Hz})$

(Eq. 1)

\section{Acoustic analysis}

Acoustic measurements of the sustained speaking vowels were speaking fundamental frequency $\left(\mathrm{F}_{0} ; \mathrm{Hz}\right)$, jitter $(\%)$, shimmer $(\mathrm{dB} ; \%)$, harmonic-to-noise ratio (HNR), and voice tremor (Fftr; Hz). Maximum phonation duration (MPD) and $\mathrm{S} / \mathrm{Z}$ ratio were obtained from sustained/a/,/s/and/z/, respectively. The middle portion of the sustained singing/a/was analyzed with the MDVP software to derive the following spectral variables: (1) $\mathrm{F}_{0}$ of $100 \%$ and (2) $\mathrm{F}_{0}$ of $0 \%$ levels of the maximum phonational frequency range (MPFR; $\mathrm{Hz})\left(\mathrm{F}_{0} 100\right.$ and $\mathrm{F}_{0} 0$, respectively); and (3) $\mathrm{F}_{0}$ range between the $100 \%$ and the $0 \%$ levels $\left(\mathrm{F}_{0} 100-0\right)$.

\section{Statistical analysis}

Subjects were classified by three age groups $[<37$; (37-45); $>45$ years of age] and, were organized into four intervals 
of time-intervals, depending on their years of professional activity $(<9,[9-20],[20-26],>26)$ [Tables 2 and 3]. This transversal study was designed to measure and compare the similarities and differences of the voice acoustic parameters among these four professional intervals. ${ }^{[29]}$

Descriptive statistics consisted of mean and standard deviation analysis of all numerical variables (Microsoft Office Excel 2003).

Inferential statistics consisted on Krusskall-Wallis, One- and Two-way ANOVA. Statistical significance was established at $\alpha=0.05$ for each variable. The parametric statistical $t$-test was use to detect significant differences between both male groups (CAP and ACC). In the absence of significant differences between the two groups in spoken and sung acoustic parameters, it was possible to treat all data as one single study group ( $N=48$ males) and thus, examine the effects of ILFN-exposure within the four time intervals of professional activity [Table 4]. One-way ANOVA was performed to detect significant differences of voice acousic parameters among four professional activity intervals. Two-way ANOVA was performed to detect significant interactions between the three age groups and the four time-intervals. Inferential statistics were performed with Statistical Package for Social Sciences (SPSS) PASW Statistics 18.

\section{RESULTS}

The first question inquired if there was a difference between the two occupational ILFN-exposed male groups (CAP and ACC) in terms of their voice acoustic parameters. $t$-test results revealed that CAP and ACC did not present significant differences in voice acoustic parameters $(P>0.05)$. Therefore it was possible to join both male ILFN-exposed groups into one single group of 48 subjects, and treat all data together [Table 4].

The next research question concerned the effects of the four professional time-intervals (associated with the total time of professional activity within ILFN-rich environments, in years) on voice acoustic parameters among the 48 occupational exposed males. For the speaking phonatory tasks, overall the mean of $\mathrm{F}_{0}$ of all vowels increased with increasing years of professional activity. One-way ANOVA revealed significant differences among the four professional activity intervals for this parameter $(P<0.05)$ [Table 5 ]. For the group with $\geq 26$ years of professional activity, One-Way ANOVA presented higher means of $\mathrm{F}_{0}$ for all vowels being significantly higher than in the others intervals $(P<0.05)$. These results for $\mathrm{F}_{0}$, however, are below the normal limits. This pattern shows that years of professional activity had a significant effect on the $\mathrm{F}_{0}$, specifically after $[20 ; 26]$ years on the job. Remarkably, these patterns were well marked, and a slight decrease of $\mathrm{F}_{0}$ was detected from the $<9$ years to the $[9 ; 20]$ professional intervals. The lower limit of $80 \mathrm{~Hz}$ was reached within the interval ( $>26$ years) [Figures $1-3$ ].

Jitter and shimmer means for/a, i, u/changed throughout the four professional intervals (See Table 5). Within the [9;20] professional activity interval, jitter mean values decreased for the three vowels. In the $[20 ; 26]$ interval, the means of jitter and shimmer for all three vowels increased. Among the $\geq 26$ yrs interval, the/a/and/i/had decreased jitter and shimmer means, while and/u/had them both increased. These results for jitter and shimmer were below the normal limits. The means of HNR of/a/were steady throughout the four professional intervals [Table 5]. These results were also below the normal limits.

\begin{tabular}{|c|c|c|c|c|c|c|}
\hline \multirow{2}{*}{$\begin{array}{l}\text { Voice acoustic } \\
\text { parameters }\end{array}$} & \multirow[t]{2}{*}{ Vowels } & \multicolumn{5}{|c|}{ Professional activity category } \\
\hline & & $<9$ & {$[9 ; 20]$} & {$[20 ; 26]$} & $\geq 26$ & $P$ value \\
\hline \multirow[t]{3}{*}{$\mathrm{F}_{0}(\mathrm{~Hz})$} & /a/ & $114.37 \pm 14.61$ & $114.36 \pm 19.37$ & $121.37 \pm 24.80$ & $156.33 \pm 37.10$ & $.003^{*}$ \\
\hline & /i/ & $130.36 \pm 29.36$ & $123.55 \pm 25.24$ & $132.35 \pm 29.14$ & $180.08 \pm 52.33$ & $.004^{*}$ \\
\hline & /u/ & $131.54 \pm 19.15$ & $126.10 \pm 19.94$ & $132.18 \pm 27.10$ & $174.45 \pm 43.65$ & $.003^{*}$ \\
\hline \multirow[t]{3}{*}{ Jitter \% } & /a/ & $0.81 \pm 0.52$ & $0.61 \pm 0.46$ & $0.67 \pm 0.51$ & $0.41 \pm 0.10$ & 0.337 \\
\hline & /i/ & $0.60 \pm 0.26$ & $0.41 \pm 0.16$ & $0.76 \pm 0.54$ & $0.75 \pm 0.57$ & 0.202 \\
\hline & /u/ & $0.70 \pm 0.29$ & $0.60 \pm 0.26$ & $0.67 \pm 0.30$ & $0.88 \pm 0.43$ & 0.399 \\
\hline \multirow[t]{3}{*}{ Shimmer (dB) } & /a/ & $0.23 \pm 0.09$ & $0.21 \pm 0.11$ & $0.22 \pm 0.09$ & $0.18 \pm 0.11$ & 0.752 \\
\hline & /i/ & $0.11 \pm 0.03$ & $0.11 \pm 0.03$ & $0.14 \pm 0.06$ & $0.10 \pm 0.03$ & 0.150 \\
\hline & /u/ & $0.13 \pm 0.10$ & $0.19 \pm 0.13$ & $0.15 \pm 0.14$ & $0.25 \pm 0.34$ & 0.502 \\
\hline HNR & /a/ & $0.13 \pm 0.13$ & $0.14 \pm 0.01$ & $0.13 \pm 0.02$ & $0.13 \pm 0.01$ & 0.315 \\
\hline \multirow[t]{3}{*}{ Fftr $(\mathrm{Hz})$} & /a/ & $3.54 \pm 2.58$ & $2.45 \pm 3.01$ & $3.11 \pm 3.39$ & $4.25 \pm 3.10$ & 0.655 \\
\hline & /i/ & $3.60 \pm 2.47$ & $2.02 \pm 2.15$ & $3.35 \pm 3.39$ & $3.64 \pm 2.90$ & 0.492 \\
\hline & $/ u /$ & $1.43 \pm 2.22$ & $2.16 \pm 1.84$ & $3.40 \pm 2.50$ & $3.95 \pm 1.99$ & 0.074 \\
\hline MPD & & $30.83 \pm 6.19$ & $22.66 \pm 7.17$ & $26.64 \pm 11.38$ & $21.62 \pm 11.21$ & 0.401 \\
\hline$S / Z$ & & $0.70 \pm 0.23$ & $0.91 \pm 0.33$ & $0.79 \pm 0.24$ & $0.73 \pm 0.33$ & 0.322 \\
\hline \multirow[t]{3}{*}{ MPFR (ST) } & $F_{0}(0)$ & $31.43 \pm 1.94$ & $29.08 \pm 2.08$ & $29.61 \pm 2.67$ & $29.00 \pm 1.91$ & 0.067 \\
\hline & $F_{0}(100)$ & $49.35 \pm 6.96$ & $55.49 \pm 4.86$ & $53.72 \pm 5.32$ & $56.81 \pm 4.41$ & 0.451 \\
\hline & $F_{0}(100-0)$ & $17.93 \pm 6.67$ & $26.41 \pm 4.95$ & $24.11 \pm 6.36$ & $27.81 \pm 3.26$ & 0.389 \\
\hline
\end{tabular}

\footnotetext{
${ }^{*} P<0.05$, ANOVA $=$ Analysys of variance; $\mathrm{HNR}=$ Harmonic-to-noise ratio; MPFR=Maximum phonational frequency range
} 


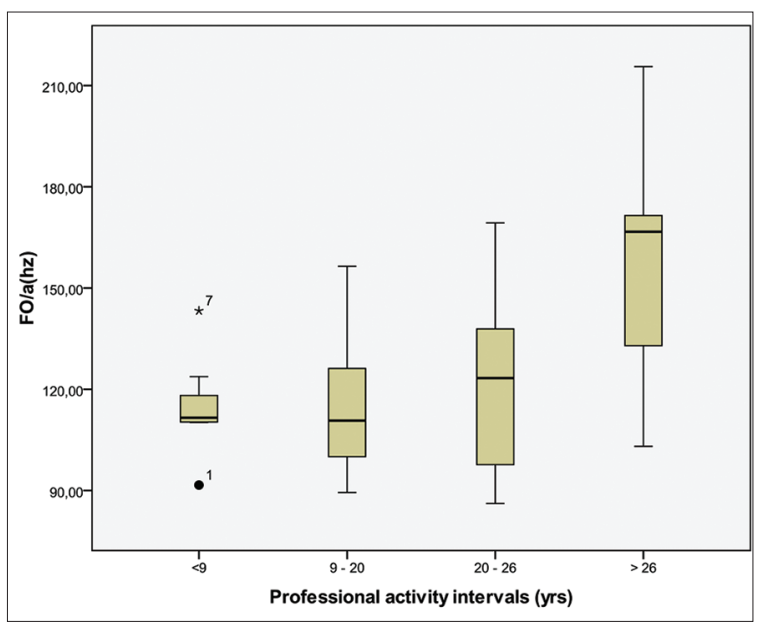

Figure 1: Box plot of speaking $F_{0}$ values of /a/ for four professional activity intervals

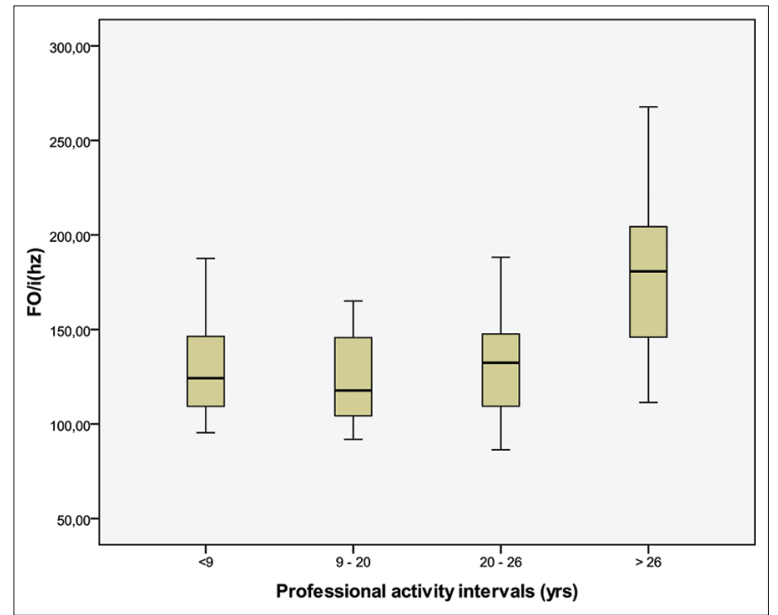

Figure 2: Box plot of speaking $F_{0}$ values of /i/ for four professional activity intervals

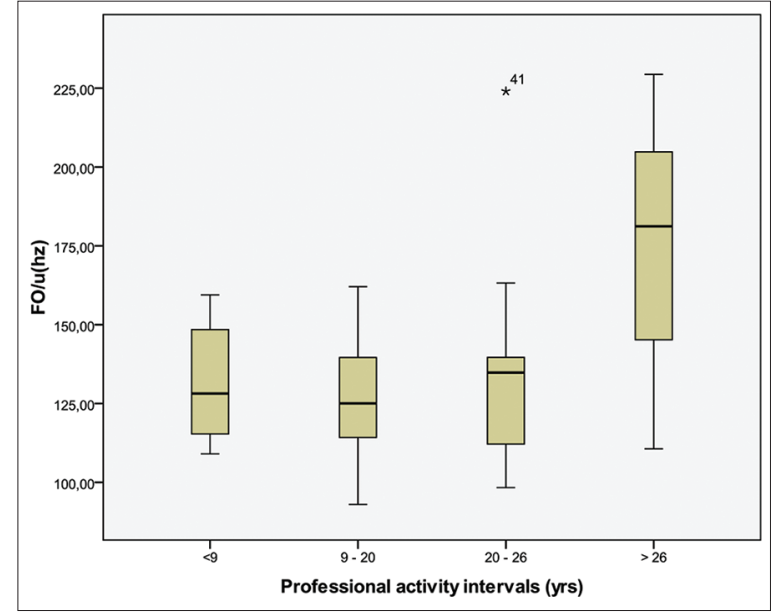

Figure 3: Box plot of speaking $F_{0}$ values of $/ u /$ for four professional activity intervals

Mean values for frequency tremor (Fftr) presented a tendency to increase throughout the four professional intervals. However, there was a slight decrease of the mean values within the second interval ([9-20] yrs) [Table5]. These Fftr results were within the normal limits.

Temporal measures, MPT and S/Z ratio, slightly changed throughout the four professional intervals. MPT means decreased within the second interval ([9-20] yrs), increased in the third interval ([20-26] yrs) and decreased again in the fourth interval ( $\geq 26 \mathrm{yrs}$ ). Means values of $\mathrm{S} / \mathrm{Z}$ ratio increased in the second interval ([9-20] yrs), and decreased within the third and fourth intervals ([20-26] yrs and $\geq 26$ yrs) [Table 5]. These results were, however, below the normal limits for $S / Z$ ratio and within the normal limits for MPT.

The MPFR revealed a pattern for $\mathrm{F}_{0}(100)$ and $\mathrm{F}_{0}(100-0)$ where mean values increased within the second interval ([9-20] yrs), decreased in the third interval ([20-26] yrs) and increased again in the forth category ( $\geq 26 \mathrm{yrs})$. For $\mathrm{F}_{0}(0)$ the mean values were steady throughout all four professional activity intervals. The upper limit of MPFR $\left(\mathrm{F}_{0} 100\right)$ varied with the amount of years of professional activity.

Two-Way ANOVA was performed to analyse the interaction between age (yrs) and professional activity intervals (yrs). Results showed a significant interaction for shimmer between the $>45$ age interval and all four professional activity intervals $(P=0.039)$. For all the others acoustic parameters, no interaction between age and years of professional activity was detected [Tables 6-8].

\section{DISCUSSION}

The purpose of this study was to analyse the effects of cumulative occupational ILFN-exposure (i.e. 3.5-36 years in four intervals) and the interaction between age (25-60 years) and occupational exposure on voice acoustic parameters among 48 male subjects. Since CAP and ACC did not presented significant differences in voice acoustic parameters, data of both groups were treated together, providing a total sample size of 48 male subjects.

The ILFN-exposed group revealed a significant increase in $\mathrm{F}_{0}(P<0.05)$ among the four professional activity intervals. There was a significant increment of the mean values of this variable for all three vowels with increasing years of professional activity. These patterns were more evident after the third intervals demonstrating that years of professional activity has an effect on $\mathrm{F}_{0}$ with increasing time of ILFN-exposure. Previous studies also revealed the same pattern. ${ }^{[16-18]} \mathrm{F}_{0}$ increased with years of professional activity years, and was unrelated to age $(P<0.05)$. These values were still within voice normal limits for this gender. 


\begin{tabular}{|c|c|c|c|c|c|c|c|c|}
\hline \multirow[t]{3}{*}{ Age } & \multirow{3}{*}{$\begin{array}{c}\text { Professional } \\
\text { activityintervals } \\
\text { (years) }\end{array}$} & \multirow[t]{3}{*}{ Vowels } & \multicolumn{6}{|c|}{$P$ value } \\
\hline & & & \multirow[t]{2}{*}{$F_{0}$} & \multirow[t]{2}{*}{ HNR } & \multirow[t]{2}{*}{ Fftr } & \multicolumn{3}{|c|}{ MPFR } \\
\hline & & & & & & $F_{0}(0)$ & $F_{0}(100)$ & $F_{0}(100-0)$ \\
\hline$<37$ & $<9[9 ; 20]$ & /a/ & 0.780 & & 0.068 & - & - & - \\
\hline$[37 ; 45]$ & {$[9 ; 20][20 ; 26]$} & /i/ & 0.468 & 0.545 & 0.070 & 0.520 & 0.484 & 0.312 \\
\hline$>45$ & {$[9 ; 20][20 ; 26][20 ; 26]$} & $/ u /$ & 0.574 & & 0.382 & - & - & - \\
\hline
\end{tabular}

ANOVA=Analysys of variance; HNR=Harmonic-to-noise ratio; MPFR=Maximum phonational frequency range

\begin{tabular}{|c|c|c|c|c|}
\hline \multirow[t]{2}{*}{ Age } & \multirow{2}{*}{$\begin{array}{l}\text { Professional activity } \\
\text { intervals (years) }\end{array}$} & \multicolumn{2}{|c|}{$P$ value } & \multirow[t]{2}{*}{ Vowels } \\
\hline & & Jitter & Shimmer & \\
\hline$<37$ & $<9[9 ; 20]$ & 0.549 & 0.209 & /a/ \\
\hline$[37 ; 45]$ & {$[9 ; 20][20 ; 26]$} & 0.994 & 0.233 & /i/ \\
\hline$>45$ & {$[9 ; 20][20 ; 26][20 ; 26]$} & 0.143 & $0.039^{*}$ & $/ \mathrm{u} /$ \\
\hline
\end{tabular}

${ }^{*} P<0.05$, ANOVA=Analysys of variance

\begin{tabular}{|c|c|c|c|}
\hline \multirow[t]{2}{*}{ Age } & \multirow{2}{*}{$\begin{array}{c}\text { Professional } \\
\text { activityintervals (years) }\end{array}$} & \multicolumn{2}{|c|}{$P$ value } \\
\hline & & MPD & $\mathrm{S} / \mathrm{Z}$ \\
\hline $\begin{array}{l}<37 \\
{[37 ; 45]} \\
>45\end{array}$ & $\begin{array}{c}<9[9 ; 20] \\
{[9 ; 20][20 ; 26]} \\
{[9 ; 20][20 ; 26][20 ; 26]}\end{array}$ & 0.189 & 0.754 \\
\hline
\end{tabular}

Perturbation measures (jitter and shimmer), HNR, voice tremor frequency, temporal measures and MPFR changed slightly throughout the professional activity time intervals. Overall, the mean values tended to decrease within the second interval (920) and increase after the third interval (20-26). However, this pattern did not achieve significance. HNR values were steady throughout the four intervals. Professional activity and age group had no interaction on voice acoustic parameters, with the exception for shimmer value for $/ \mathrm{u} / \mathrm{in}$ the last age group $(>45)$. Although $\mathrm{F}_{0}$ increased with age and years of professional activity years [Figure 4-9], two-way ANOVA did not reveal a significant interaction between these two dependent variables.

When compared with normative data, different patterns were revealed, reflecting slight differences of mass, tension, and biomechanical characteristics of vocal folds, reduced upper and lower physical limits of the phonatory system, and inefficient coordination between the respiratory and phonatory system. No indication of glottal closure inefficiency nor problems in the amplitude perturbation were present. Comparative studies revealed $\mathrm{F}_{0}$, HNR and Fftr within normal limits and significant differences on perturbation and temporal measures, which were unrelated to age and to years of professional activity. ${ }^{[15,17]}$

The results obtained in this study are likely to be in accordance with observations made through bronchoscopic examinations performed on 30 volunteer flight attendants, wherepink (small sub-mucosal vascular-like) lesions were located distally in both tracheal and bronchial trees, and distributed bilaterally near the spurs, as well as on the vocal folds. ${ }^{[30]}$ Histological and ultrastructural studies of biopsy material taken from these pink lesions revealed an abnormally thickened basal lamina due to the presence of collagen, and neovascularization disclosing very thickened small blood vessels with scarce lumen. No inflammatory cellularity nor processes were observed, nor was there retraction of neighboring structures observed in the vicinity of collagen fibers. ${ }^{[30]}$ These morphological changes may, at least in part, be responsible for the changes in the voice acoustic parameters described herein.

Pilots and crew members are considered Type II - Professional voice. Since voice acoustic analyses are sensitive to the laryngeal and respiratory changes, it may be possible to use this methodology to trace voice acoustic changes among other populations occupationally exposed to ILFN.|20]

\section{CONCLUSIONS}

VAD is a whole-body systemic pathology caused by ILFN-exposure and characterized by the abnormal growth of extra-cellular matrices, namely elastin and collagen. Since (a) CAP and ACC are occupationally exposed to ILFN, and (b) ILFN targets the respiratory system, phonatory tasks were performed to analyze voice acoustic parameters, and to determine the interaction of age and cumulative years of professional activity on these voice parameters.

Cumulative years of professional activity have a significant effect on $\mathrm{F}_{0}$ whichincreased significantly with the number of years of professional activity, an effect that was unrelated to age. $\mathrm{F}_{0}$ reflects slight differences of mass, tension, and biomechanical characteristics of the vocal foldspossibly mirroring histological changes. 


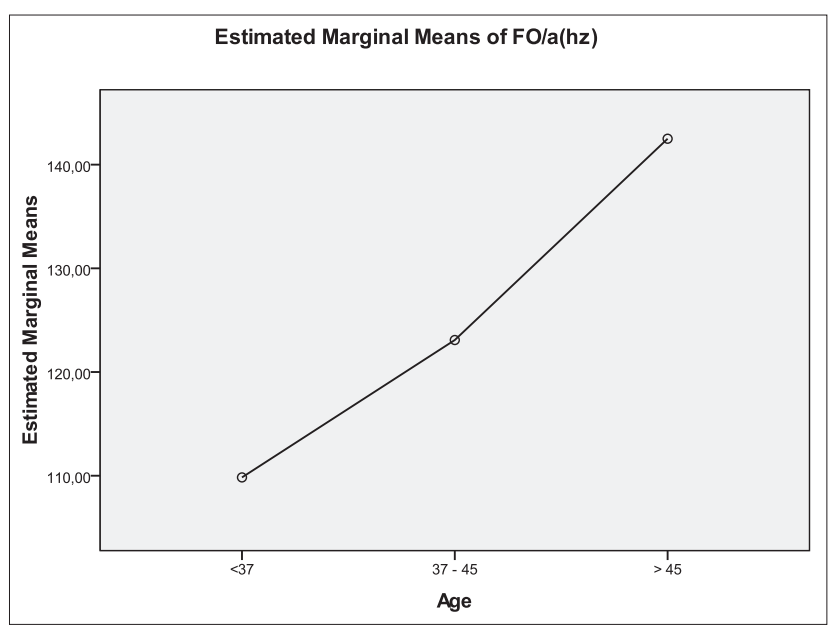

Figure 4: Increase of mean value of speaking $F_{0}$ for /a/, with increasing age group

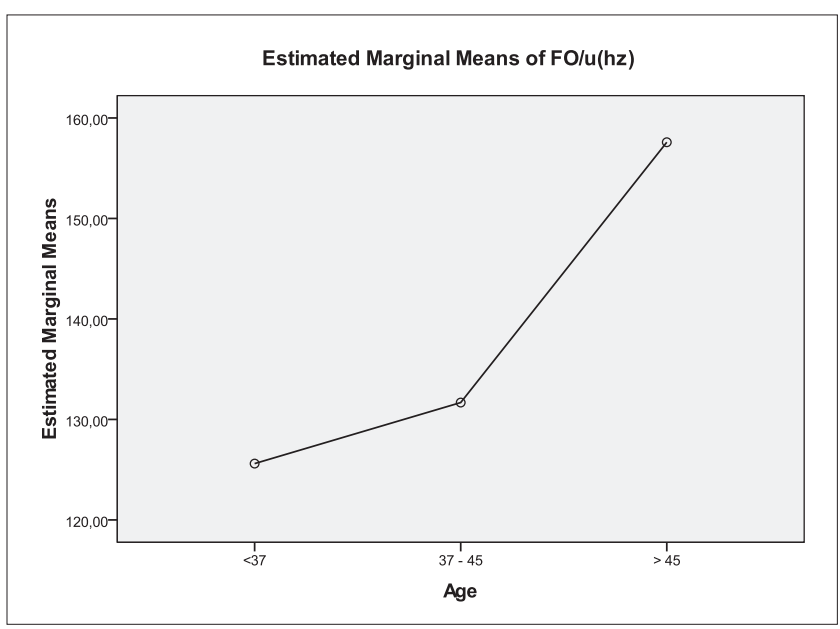

Figure 6: Increase of mean value of speaking $\mathrm{F}_{0}$ for $/ \mathrm{u} /$, with increasing age group

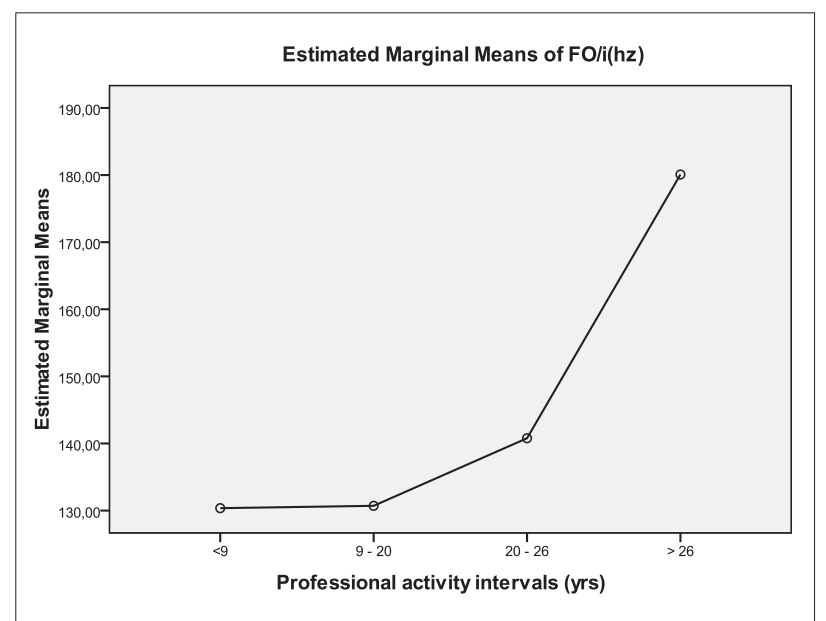

Figure 8: Increase of mean value of speaking $F_{0}$ for $/ \mathrm{i} /$, with increasing professional activity intervals

Future longitudinal voice acoustic analyses should be performed on the same subjects throughout the duration of their professional activity to determine how these parameters change over the ILFN-exposure years. Moreover, additional

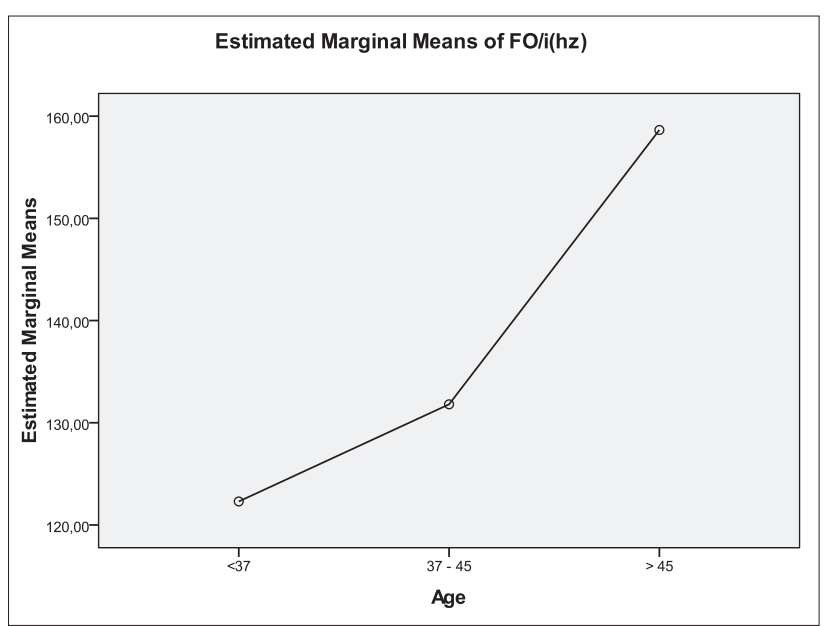

Figure 5: Increase of mean value of speaking F0 for /i/, with increasing age group

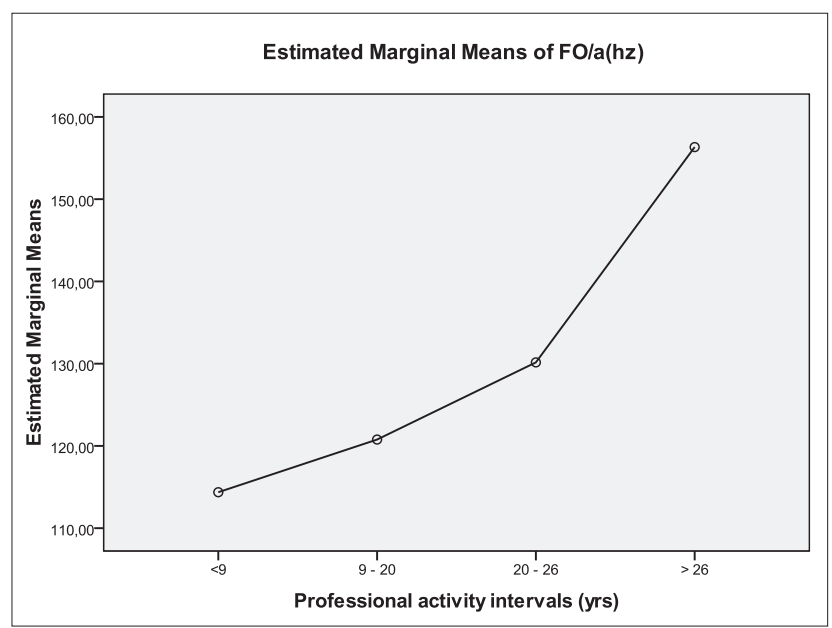

Figure 7: Increase of mean value of speaking $F_{0}$ for $/ a /$, with increasing professional activity intervals

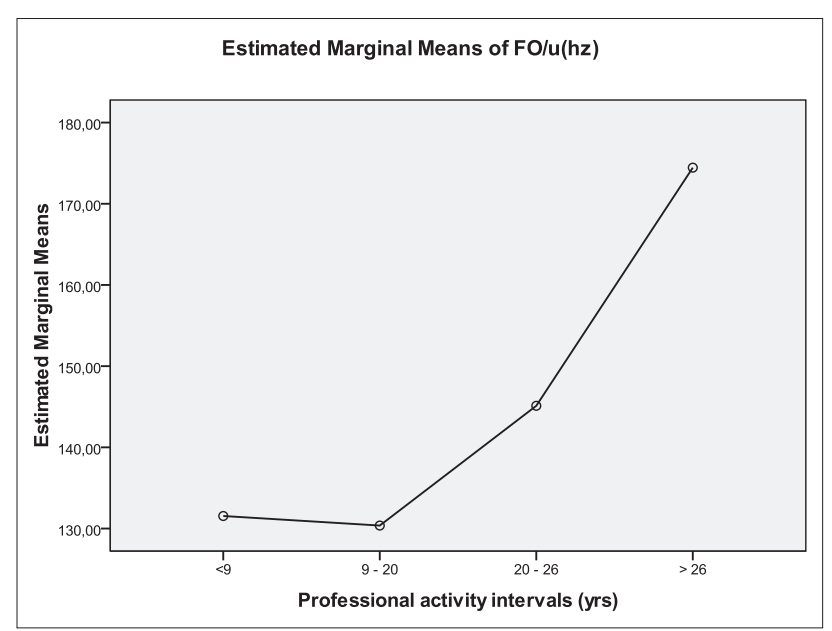

Figure 9: Increase of mean value of speaking $F_{0}$ for vowel /u/, with increasing professional intervals

research correlating data from physiological and histological studies could greatly contribute to the relevance of including acoustic voice parameter analyses as a complementary diagnostic tool for VAD. 


\section{REFERENCES}

1. Branco NA, Alves-Pereira M. Vibroacoustic disease. Noise Health 2004;6:3-20.

2. Castelo Branco NA. The clinical stages of vibroacoustic disease. Aviat Space Environ Med 1999;70:A32-9.

3. Alves-Pereira M, Reis Ferreira JM, Joanaz de Melo J, Motylewski J, Kotlicka E, Castelo Branco NA. Noise and the respiratory system. Rev Port Pneumol 2003;9:367-79.

4. Branco NA, Ferreira JR, Alves-Pereira M. Respiratory pathology in vibroacoustic disease: 25 years of research. Rev Port Pneumol 2007;13:129-35.

5. Marciniak W, Rodriguez E, Olszowska K, Atkov O, Botvin I, Araujo A, et al. Echocardiography in 485 aeronautical workers exposed to different noise environments. Aviat Space Environ Med 1999;70:A46-53.

6. Monteiro MB, Reis Ferreira J, Mendes CP, Alves-Pereira M, Castelo Branco NA. Vibroacoustic disease and respiratory pathology III - Tracheal and bronchial lesions. ProcINTEERNOISE2004; Prague, CzechRepublic, August 22-25: No. 638.

7. Castelo Branco NA. A unique case of vibroacoustic disease: A tribute to an extraordinary patient. Aviat Space Environ Med 1999;70:A27-31.

8. Castelo Branco NA, Alves-Pereira M, Martins dos Santos J, Monteiro E. SEM and TEM studyofratrespiratoryepitheliaexposed to lowfrequency noise. In: Mendez- Vilas A, editor. Science and Technology Education in Microscopy: An Overview, Formatex. Vol. II. Badajoz, Spain; 2002. p. 505-33.

9. Reis Ferreira J, Mendes CP, Castelo Branco NA, Monteiro E, Alves-Pereira M. Thehumanlungand pleura in vibroacousticdisease. Proc $8^{\text {th }}$ Intern Conf Noise as a Public Health Problem (ICBEN) Rotterdam: Holland; 2003. p. 386-7.

10. Reis Ferreira JM, Couto AR, Jalles-Tavares N, Castelo Branco MS, Castelo Branco NA. Airflow limitations in patients with vibroacoustic disease. Aviat Space Environ Med 1999;70:A63-9.

11. Hirano M. Morphological structure of the vocal cord as a vibrator and its variations. Folia Phoniatr (Basel) 1974;26:89-94.

12. Gray S, Hirano M, Satto K. Molecular and cellular struture of the vocal fold tissue. In: Titze IR, editor. Vocal fold physiology: Frontiers in basic science: 1-36; San Diego: Singular Publishing Group, 1993.

13. Mendes A, Castro E. Acoustic analysis of voice assessment: phonatory tasks and acoustic parameters. Rev Port Otorrinolaringol Cirurgia Cérvico-Facial 2005;43:127-36.

14. Colton R, Casper J. Understanding voice problems: A physiological perspective for diagnosis and treatment. Baltimore: Williams and Wilkins; 1990.

15. Mendes AP, Alves-Pereira M, Castelo Branco NA. Voice acoustic patterns of patients diagnosed with vibroacoustic disease. Rev Port Pneum 2006;12:375-82.

16. MendesAP, Graça A, Santos CP, Galvão A, Carvalho RO, Sousa MJ, et al. Voice acoustic analyses in airline cabincrew members. INTERNOISE 2008, Shanghai, China. 2008.

17. Mendes AP, Graça A, Jorge A, Alves-Pereira M, Castelo-Branco NA, Freitas A, et al. The effects of ILFN-exposure on voice acoustic parameters of commercial cabin crewmmbers. J Laryngol Voice 2012;2:70-80.

18. Mendes AP, Santos CP, Graça A, Galvão A, Carvalho RO, Sousa MJ, et al. Voice acoustic analyses of commercial airline pilots. INTERNOISE 2008, Shanghai, China. 2008

19. Alves-Pereira M, Castelo Branco MS, Motylewski J, Pedrosa A, Castelo Branco NA. Airflow-induced infrasound in commercial aircraft. INTERNOISE 2001, The Hague, Holland: 1011-14.

20. Scherer RC, Vail VJ, Guo CG. Required number of tokens to determine representative voice perturbation values. J Speech Hear Res 1995;38:1260-9.

21. Mendes A, Costa A, Martins A, Fernandes A, Vicente S, Freitas T. [Contributions for thecontstructionof a phoneticallybalancedtext for European Portuguese.] Revista CEFAC - Speech, language, hearing sciences and education journal. 2012;14:910-7.

22. Hollien H, Dew D, Phillips P. Phonationalfrequency ranges ofadults. J Speech Hear Res 1971;14:755-60.

23. Zraick RI, Nelson JL, Montague JC, Monoson PK. The effects of task on determination of maximum phonational frequency range. J Voice 2000;14:154-60.

24. Mendes AP, Rothman HB, Sapienza C, Brown WS Jr. Effects of vocal training on the acoustic parameters of the singing voice. J Voice 2003;17:529-43.

25. Titze IR, Winholtz WS. Effect of microphone type and placement on voice perturbation measurements. J Speech Hear Res 1993;36:1177-90.

26. KayPENTAX. Computerized Speech Lab (Version 4500) [Computer Software]. Lincoln Park: A Division of PENTAX Medical Company; 2007.

27. Titze I. Principles of the voice production. Englewood Cliffs: Prentice Hall; 1994.

28. Ventry I, Schiavetti N. Evaluating research in speech pathology and audiology. $2^{\text {nd }}$ ed. New York: Macmillan; 1986.

29. Koufman JA, Isacson G. Voice Disorders. Philadelphia: W. B. Saunders; 1991.

30. Ferreira JR, Monteiro MB, Tavares F, Serrano I, Monteiro E, Mendes $\mathrm{CP}$, et al. Involvement of central airways in vibroacoustic disease patients. Rev Port Pneumol 2006;12:93-105.

Cite this article as: Mendes AP, Bonanca I, Jorge A, Alves-Pereira M, Castelo Branco NA, Caetano M, et al. Voice acoustic profile of males exposed to occupational infrasound and low-frequency noise. J Laryngol Voice 2014;4:12-20.

Source of Support: Nil, Conflict Interest: No. 